\title{
Periferia Paulistana Da Necessidade de Inserção
das Habitações de Interesse Social
na Malha Urbana Da Necessidade de Inserção
das Habitações de Interesse Social
na Malha Urbana Da Necessidade de Inserção
das Habitações de Interesse Social
na Malha Urbana
}

Este artigo relata a pesquisa sobre a avaliação pós-ocupação (APO) de habitação autoconstrulda por populaçōes de baixa renda, aplicada em loteamentos situados no Butantã - SP, no perlodo 1985-1988.

Enfatiza a necessidade de extrapolar esta avaliação, particularmente no que se refere aos estudos comportamentais, para o espaço público, a infra-estrutura urbana e o bairro, a fim de se procurar mecanismos para efetivamente inserir estes bolsōes de probreza no contexto urbano.

\section{Abstract}

This article presents a Post-Occupancy Evaluation (POE) research applied to self-built low-income settlements located in a Western São Paulo's city suburb, during the period 1985-1988. It emphasizes the need of a broader evaluation, particulary faced to public spaces, urban infra-structure and low-income districts as a whole, in order to find out ways to include this islands of poverty into the urban context. 


\section{Quadro 1}

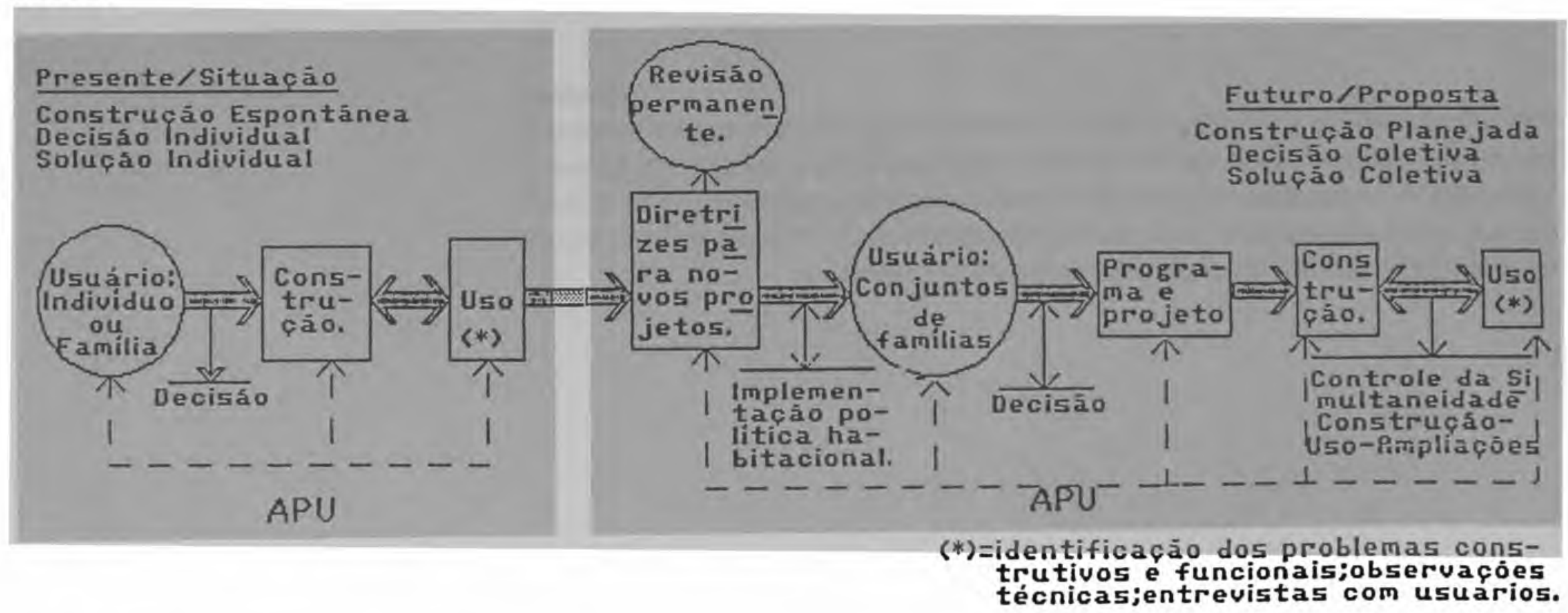




\section{Introduçăo: O Método de Avallação Pós-Ocupação (APO) Aplicado em Habitaçōes Autoconstruldas}

No perfodo 1985-1988 foi desenvolvida pesquisa, cujo principal escopo na época, era a introduçăo de uma metodologia cientffica de APO à realidade nacional, como um instrumento de realimentação do processo de produçăo e uso (operação e manutenção) de edificaçð̃es, levando em consideraçăo os diversos niveis de decisão dos agentes produtivos (sejam estes, arquitetos, construtores e, até mesmo, autoconstrutores) bem como os niveis e tipos de decisăo tomados pelos usuários (sejam, ou não, tambêm autoconstrutores das edificações em questão).

Uma vez que a APO, até 1988, enquanto metodologia de projeto, foi somente aplicada no Brasil, de forma esporádica, pretendeu-se, com esta pesquisa, que tem como base de estudo de caso, amostragem de unidades habitacionais autoconstruldas por populaçăo de baixa renda (até US $\$ 40.00$ per capita), situadas na porção do Municlpio de São Paulo, abrangida pela Administração Regional do Butantã (A.R.Bt), iniciar um processo gradativo e através de metodologia cientffica, de sistematização da APO no sentido de:

a) A curto prazo: detectar e minimizar problemas existentes em edificaçōes em uso (reformas e adaptaçōes);

b) a médio prazo: aprimorar e aferir a metodologia para aplicação da APO. Note que a APO, enquanto pesquisa e área do conhecimento no åmbito do projeto de edificações, não pode ser apresentada enquanto uma metodologia-modelo, única e padronizada, mas pode e deve ser aplicada em vários niveis de profundidade, dependendo dos recursos financeiros disponfveis para a realização da pesquisa. Nestes vários niveis de profundidade, devem ser considerados os distintos repertórios das populaçōes envolvidas (por exemplo, no caso de habitaçōes autoconstruldas por populaçōes de baixa renda, tem-se elevados niveis de analfabetismo), as condiçōes ambientais e sócioeconômicas da região em que está sendo aplicada, e, a existência, ou não, de técnicos especializados envolvidos no planejamento e orientaçăo do processo de produçăo;'

c) a longo prazo: determinar diretrizes para futuros projetos; uso, operação e manutenção, no caso, de habitaçōes a serem autoconstruldas e geridas a partir de uma poltitica habitacional a ser definida por Órgãos Pủblicos, nos niveis nacional, estadual e municipal. Nesta linha, a longo prazo, com base nos resultados de APOs aplicadas repetitivamente, poder-se-å também complementar normas de desempenho de habitaçōes para populaçăo de baixa renda.

A seguir, pode-se visualizar o Quadro 1 que demonstra, através de fluxograma esquemático, as etapas de desenvolvimento da APO, no caso de habitaçōes autoconstruldas na periferia paulistana.

Note, no interior da moldura à esquerda (Quadro 1), como se desenvolveu a aplicação da APO no caso desta pesquisa. Ocorre que a APO é um processo dinåmico, evolutivo e sistemático, ou seja, deve, em perlodos regulares, ser repetida para os mesmos estudos de caso, até mesmo para se aferir a eficácia (ou a ineficácia) das propostas implementadas a partir da APO anterior, o que pode, por conseguinte, sugerir alterações e/ou complementações das diretrizes de projeto formuladas. Assim é que, conforme demonstra o fluxograma inserido na moldura à direita, deve até mesmo como mecanismo de aprimoramento do próprio método, passar para um estágio mais avançado e sofisticado em que o objetivo principal, é a realimentação das diretrizes de projeto oriundas das APOs desenvolvidas em estágios menos elaborados, anteriores.

Este estágio mais avançado diz respeito, na verdade, ao efetivo controle de qualidade do ambiente habitacional construldo, tendo em vista, năo só o seu desempenho flsico, mas, também a satisfação de seus usuários. 


\section{Desenho 1}

Localizaçāo da A.R.Bt no Municlpio de São Paulo.

Fonte: Sempla, 1985, p. 15.

\section{Desenho 2}

Localização das Habitações

Autoconstruifdas Selecionadas, no Butantã.
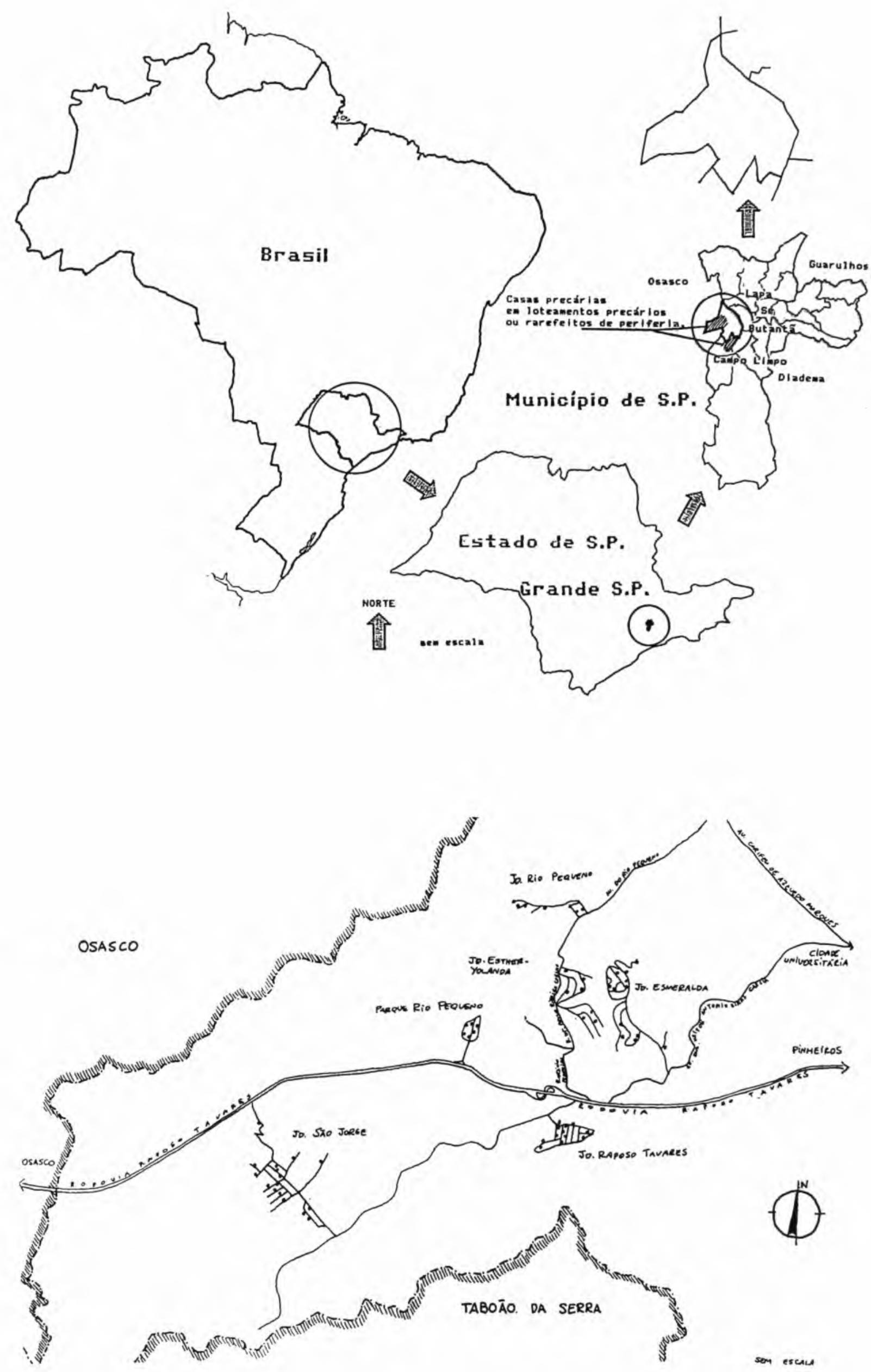


\section{Características Gerais da Habitaçăo de Baixa Renda na Metrópole Paulistana: a Década de 80}

$\mathrm{Na}$ década de 80, nada de eficaz foi feito (em termos de polfticas habitacionais), para desacelerar o processo nacional de aumento do déficit habitacional. Muito pelo contrário, ęste quadro se agravou, particularmente para as classes de interesse social, ou seja, para as famnias com renda mensal até 3 salários mínimos, aonde se encontra cerca de $76 \%$ do déficit habitacional brasileiro. Das cerca de 13,7 milhöes de unidades, edificadas necessárias para cobrir o déficit habitacional brasileiro em áreas urbanas no perfodo $80-90$, pelo menos 10,5 milhōes deveriam cobrir as necessidades de famlias com renda mensal até 3 salários mínimos. (Albuquerque, 1985)

Este panorama nacional, diz respeito, particularmente, às regiōes metropolitanas, encontrando-se o Municlpio de Săo Paulo, por razōes já bastante conhecidas e discutidas, entre aquelas em que o problema da moradia para população de baixa renda é um dos mais contundentes, nāo tendo sido o mercado público, na década de 80, capaz de absorver mais do que $5 \%$ da populaçăo de Săo Paulo. (Taschner, 1986)

O Plano Diretor do Municlpio de São Paulo (1985), coloca que já no infcio da referida década (1983), as denominadas habitaçōes subnormais existentes no município, representavam $55 \%$ da população, com a seguinte distribuição:

\section{favela}

aluguel em cortiço e casa precária

casa própria auto construlda precária

Fonte: Villaça, 1986 p.62.

Ou seja, $22 \%$ da população municipal mora em habitações próprias autoconstruldas. Esses significativos $22 \%$ podem se elevar ainda mais, caso sejam também considerados os inquilinos de casas precárias. Este contexto possivelmente se reproduz de forma muito semelhante em outras periferias de áreas urbanas brasileiras, enfatizando a necessidade de uma avaliação (pós-ocupação) do modo de produçăo e uso desta tipologia de moradia. Note que, dentre as sub-habitaçôes, a autoconstruçăo ${ }^{1}$ de periferia $^{2}$, abriga um contingente populacional, no mfnimo quatro vezes superior ao das favelas. É dentro deste contexto que se inserem as unidades habitacionais situadas na área da A.R.Bt, submetidas à APO.

\section{Características Gerais da Área Compreendida pela A.R.Bt}

Selecionou-se para pesquisa exploratória no åmbito da APO, a A.R.Bt (esta administração regional é recente, tendo sido criada em 1973, através do desmembramento da Administração Regional de Pinheiros), pois esta área abriga loteamento particularmente aqueles situados junto aos limites municipais, com caracterlsticas flsico-sócio-econômicos, nitidamente de franja periférica. Localiza-se na Zona Oeste do Municipio, inserindo-se parte de sua área total na área periférica do Municlípio, população estimada de 412.634 habitantes e área bruta de 5000 hectares (Sempla, 1985). Faz limite com os Municlpios de Osasco, Taboăo da Serra, Cotia, assim como com as Administrações Regionais da Lapa, Pinheiros e Campo Limpo, conforme demonstra o Desenho 1 que se segue.

A A.R.Bt apresenta densidade demográfica baixa, sendo que $45 \%$ de seu território Ifquido está vazio. Junto a sua área mais central possui diversas áreas institucionais (Cidade Universitária, Instituto Butantã e o Jockey Club), assim como concentraçőes significativas de habitaçōes de elevado padrão. Por outro lado, conforme poderá ser visualizado no Desenho 2, constante do item 4 que se segue, abriga também diversos loteamentos de médio e baixo padrão, especialmente ao longo das Rodovias Raposo Tavares e Regis Bittencourt, perfazendo $39 \%$ dos domicnios da A.R.Bt, cujas famnlias encontram-se na faixa de renda entre 0 e 7 salários mínimos.

(1) E Importante frlsar que o nasso objeto de estudo năo á a sub-habltaçăo - favela, caracterizada pela ocupaça de terrenos clandestlnos por melo de habltaços tipo "barraco" ou tipo rústlco f... om cuja construçáso houvesse predominâncla de material Improvisado, tals como paredes de taipa náo revestlda, madeira aprovellada ou materlal de vasilhame, piso de terra, madelra aproveltada ou tijolo de barro cozido ou adobe; e cobertura de madelra aproveltada, palha, sapé ou materlal de vasilhame - IBGE, 1988). Tratam-se sim, da sub-habitaçáo, próprla autoconstrulda de forma Indlvidualizada, assentada em terreno comerclallzado. Ou seja, dos casos em que o próprlo proprletárlo, seus famillares ou agregados, com ou sem empreltadas parclais, conceberam, construfram $\theta$ estăo utllizando $\theta$ mantendo es pontaneamente (sem a responsabilidade de técnlcos habilitados) a unidade Isolada. E, ao contrá. ro dos barracos, são construfdas com materlals convenctonais de construçăo... exatamente como em qualquer morada burguesa". (Taschner, 1986 p. 275)

(2) -... As áreas onde os serviços públicos săo precárlos ou inexlstentes e de acesso dificll, onde vive uma populaçąo com balxo nlvel de renda, contando com precárlas condiçరes materlals", ou, "balrros que se assemelham a canteiros de obras, e, mantem essas caracterlsticas por multos anos năo raramente por mals de 20 anos, ate chegar os primelros elementos de Infra-estrutura". (Tas chner, Mautner, 1982, p. 59, texto reduzido) 


\section{Gráfico 1}

Quantidade de amostras quanto ao nivel de qualidade do Transporte Coletivo.

Fonte: Ornstein, 1988, p. 83.

\section{Gráfico 2}

Quantidade de amostras quanto ao nivel de qualidade do Comércio e Serviços.

Fonte: Ornstein, 1988, p. 83.

\section{Gráfico 3}

Quantidade de amostras quanto à Existência de Infra-Estrutura.

Fonte: Ornstein, 1988, p. 84.

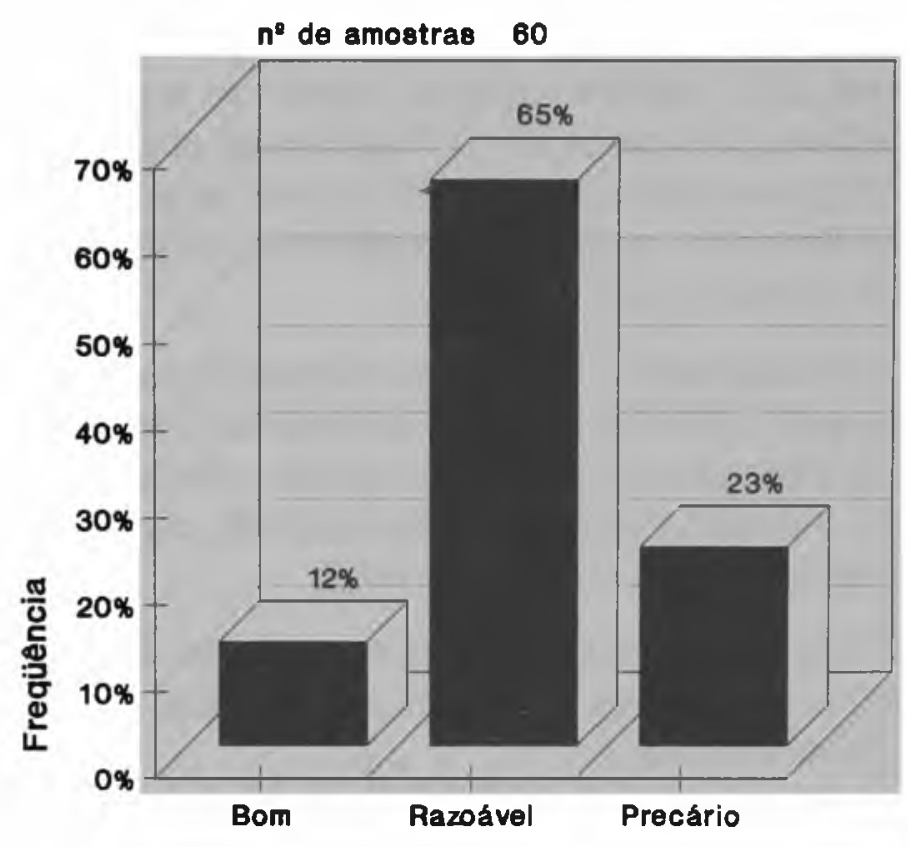

Nivel de Qualidade
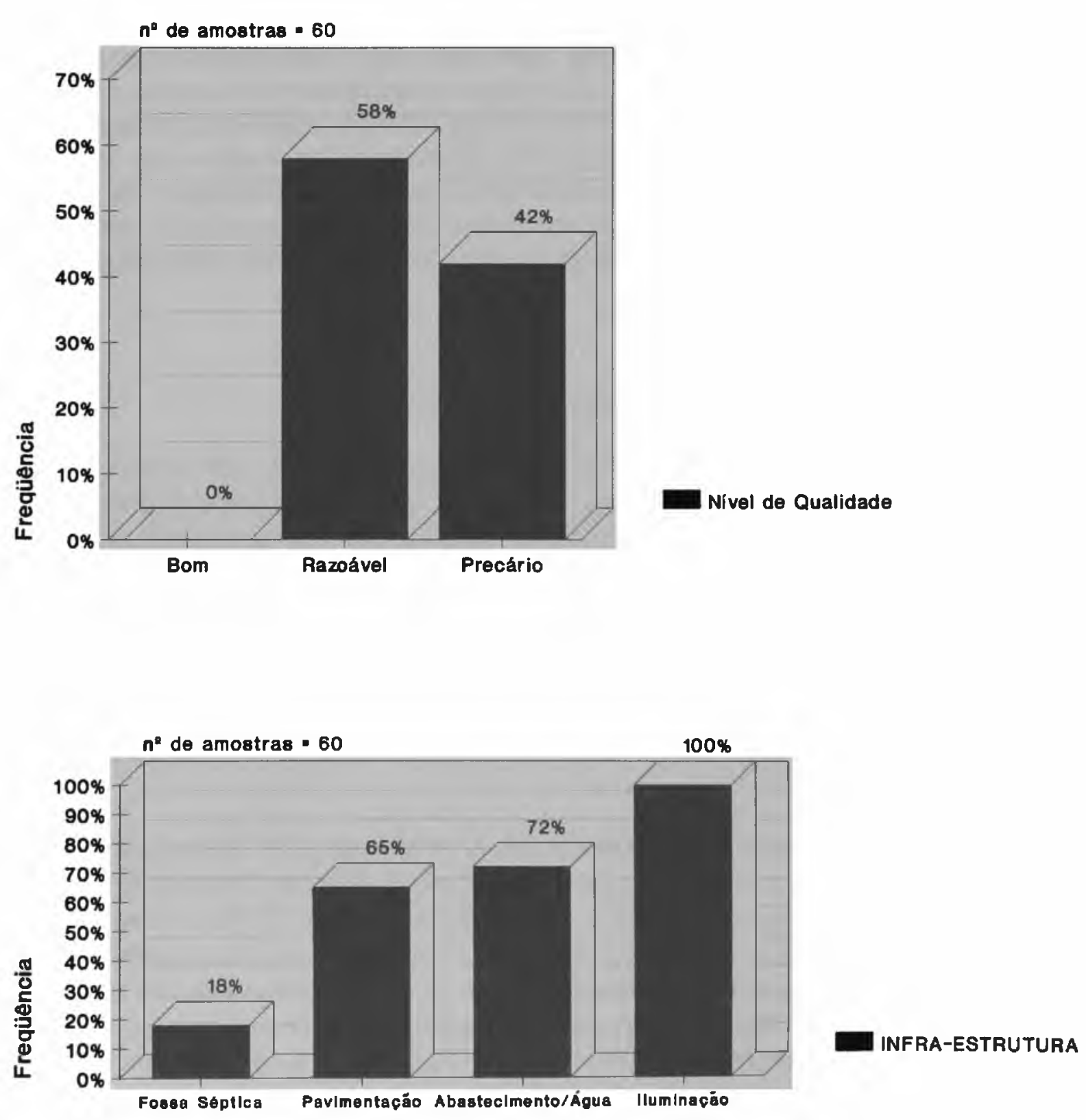


\section{Delimitação da Pesquisa: as Habitações Autoconstruídas por População de Baixa Renda Situadas na A.R.Bt, Submetidas à APO}

A questão da autoconstrução de habitaçōes na periferia de São Paulo, passa pela questão da mais-valia do trabalho de mão-de-obra não especializada (via de regra, autoconstrutores de fins de semana), a qual, se devidamente organizada em mutirões e gerenciada, tecnicamente, talvez seja a única solução factivel para o déficit habitacional no momento. Por outro lado, a situação como um todo é complexa e interdisciplinar, sendo, de fato, as soluçōes encontráveis, nas esferas nacional, regional e dos grupos comunitários. Assim, a gama de áreas do conhecimento incluldas na APO é bastante extensa. Por este motivo, optou-se por aplicá-la em profundidade e de forma detalhada em uma base emplrica limitada, qual seja, 60 (sessenta) habitaçōes autoconstruldas por população de baixa renda, delimitando-se, a priori, para tanto, os bolsōes da A.R.Bt, em que poderiam ser encontradas concentraçōes significativas destas tipologias habitacionais.

Para se delimitar estes bolsōes de loteamento "dito populares" no Butantā, procedeu-se a um levantamento junto à Secretaria da Administraçāo Regional do Butantã, compreendendo o perlodo de março de 1973 (data inicial de formaçāo desta Administraçāo Regional) até agosto de 1985, que indicou, para o referido perlodo, a existência de 855 alvarás de construção e 131 autos de conclusão para moradias econômicas ${ }^{3}$.

Foram, então, selecionadas 60 unidades habitacionais amostrais, perfazendo aproximadamente $7 \%$ do total de unidades com alvarás de construção situadas em seis loteamentos. (Desenho 2).

Estas 60 unidades habitacionais estão distribuldas em seis loteamentos conforme Tabela I ao lado.

A partir de levantamentos especfficos nestas 60 unidades pode-se depreender, além das condiçōes fisicas dos envólucros em questāo, as condiçōes da super e da infraestrutura urbanas dos loteamentos pesquisados, visando definir o grau de inter-relação entre o envólucro autoconstruldo e o contexto urbano em que está inserido. Os grăficos a seguir demonstram algumas destas caracterlsticas:

Para os Gráficos 1 e 2, ou seja, para se conhecer os niveis de satisfação dos moradores das habitações selecionadas (Desenho 2 e Tabela I) no que se refere ao transporte coletivo e ao comércio e serviços existentes no Butantã, foi definida uma escala de valores com três pontos, a sér respondida pelos chefes de famflia em questão (no caso $60)$. Estabeleceu-se uma escala de valores simplificada (apenas com três pontos), dado o baixo nivel sócio-cultural das populaçōes envolvidas. Suscintamente, os critérios que definem cada um dos três pontos são os que se seguern:

Bom - existe o item em questão nas proximidades de sua casa, sendo possivel atingilo à pé e usufruir satisfatoriamente do transporte, comércio ou serviço.

Razoável - existe o item em questão nas proximidades de sua casa, embora, para atingi-lo, seja necessário percorrer uma distância mínima de $1000 \mathrm{~m}$. O tipo de transporte, serviço ou comércio oferecidos deixa algo a desejar.

- Precário - não existe o item em questão ou para atingi-lo é necessário percorrer mais do que $2000 \mathrm{~m}$ de distância. Uma vez alcançado, é grande a insatisfação quanto ao transporte, serviços ou comércio oferecidos.

Quanto ao Gráfico 3, trata-se da tabulação feita pela própria equipe técnica (pesquisadores), quanto à existência (ou não) de infra-estrutura básica nos locais em que estavam situadas as 60 habitaçôes selecionadas.

'Verifica-se, atravês dos Gráficos 1 e 2, que os bolsōes periféricos em questāo, localizados no Municlpio de São Paulo, do ponto de vista de seus moradores, no que diz respeito ao transporte coletivo e ao comércio e serviços, situam-se entre razoável e precário, não havendo ausências significativas de nenhum serviço público (ou mesmo privado) essencial. Situação semelhante ocorre no que diz respeito à infra-estrutura
Tabela I

Distribulçăo Percentual de Amostras por Loteamento.

\begin{tabular}{lcc}
\hline Loteamento & Quantldade & $\%$ \\
\hline Jardlm Esmeralda & 12 & 20,0 \\
Jd. Esther Yolanda & 08 & 13,3 \\
Jd. Raposo Tavares & 12 & 20,0 \\
Jd. Rlo Pequeno & 06 & 10,0 \\
Pq. Rlo Pequeno & 06 & 10,0 \\
Jd. Săo Jorge & 16 & 26,7 \\
\hline Total & 60 & 100,0 \\
\hline
\end{tabular}

(3) A delimitaçăo deste universo (855 alvarás de construçāo), deveu-se ao fator custo de pesquisa, assoclado à profundldade com que foram avalla das as habltaçðos seleclonadas. Sabo-se, no entanto, que existem no Butantå um número multo malor de habltaçbes autoconstruldas do que aquele cadastro na Secretarla, ou seja, Inúmeras habitaçōes llegais ou clandestlnas, embora Implantadas em terrenos, na maloria das vezes, comerclallzados regularmente, Outra forma pos sivel para se delimitar este universo (porém mals oneroso), serla através de pontos de água ou de luz, respectlvamente cadastrados na SABESP Companhla de Água e Esgoto do Estado de Săo Paulo ou da ELETROPAULO - Eletricidado de Såo Paulo S.A. 
(Ǵráfico 3). Na realidade, o Butantã é um bairro razoavelmente consolidado se comparado com outras periferias pesquisadas, tais como São Miguel Paulista. (Taralli et al. 1989)

\section{A APO e alguns de seus Resultados}

Este trabalho, nitidamente voltado para o invơlucro construfdo (ou em construção) concluiu pelo potencial do método que colabora na compreensão do objeto de estudo e no desenvolvimento de recomendações para o seu melhor desempenho, se necessário. Quanto ao aprimoramento em si da APO, este vem ocorrendo através de sua aplicaçăo sistemática e repetitiva em estudos de caso semelhantes, o que permite a incorporação paulatina de incrementos e ajustes ao processo de pesquisa.

No que se refere à hipótese corrente de que a autoconstruçăo espontânea apresenta eficiência econômica, detectou-se que cerca de $75 \%$ das unidades amostrais levantadas apresentaram de fato custos por metro quadrado inferiores a de uma unidade habitacional completa, projetada segundo padrão de habitabilidade condizente com uma habitação de interesse social, para servir como modelo comparativo de referência no estudo. Todavia em uma análise mais profunda, confirmou-se que, nestes casos, custos reduzidos ocorriam em habitaçōes inacabadas e desconfortáveis.

Seguindo o mesmo raciocínio, custos elevados de unidades amostrais em relação a unidade padrăo, indicaram o superdimensionamento de peças estruturais, via de regra desnecessário no caso destas pequenas habitaçōes espontâneas, o que comprova a distorção da hipótese.

Para se obter estes resultados, foram levantados dados prévios relativos ao perfil sócio-econômico destas famlias, ao lote e à infra-estrutura existente nos locais selecionados. Estes dados, associados a reflexōes posteriores sobre a necessidade da avaliação complementar de espaços públicos, no caso de habitações de interesse social, é que originaram este artigo.

Verifica-se, através de trabalhos desenvolvidos e em desenvolvimento pela Companhia Metropolitana de Habitação de São Paulo (COHAB-SP), pela Companhia de Desenvolvimento Habitacional do Estado de São Paulo $(C D H)$ e, mais recentemente, através de alguns conceitos incorporados à APO na FAUUSP, na linha das relaçōes dialéticas entre comportamento humano e ambiente construldo (Bechtel, Marans, Michelson, 1987), que a questão extrapola o simples invólucro construldo isolado, passando pela necessidade de inserção destes invólucros no contexto urbano.

Assim é que uma outra hipótese a ser aqui analisada é a de que bolsões de autoconstruçōes espontâneas e conjuntos habitacionais segregam social e fisicamente de forma semelhante seus moradores.

(4) Quanto à questăo da segregaçáo social, existe uma ampla literatura nesta linha, cuja abordagem desenvolvida, no caso brasilelra, multo mals por cientistas soclais do que por arquitetos, segundo uma visắo de complementariedade aos aspectos relativos à segregação (e iso lamento espacial). A maior parte destas pesqui sas estáo relaclonadas a minorias. Destacam-se, a pesquisa desenvolvida por Sarah Feldman (dlssertaçáo de mestrado, FAUUSP, 1989), enfocan do a questáo das segregaços espaciais urbanas em Săo Paulo, a luz da territorlalizaçăo da prostitulçáo feminina, no perfodo de 1924 até o infcio da década de 70. Estudos nesta área, também săo desenvolvidos há várias décadas nos palses desenvolvidos, por equipes interdisciplinares. Destaca-se, à tfulo de exemplo, a pesquisa realizada por Jacquellne Leavitt (arquiteta) e Susan Saegert (psicóloga) em 1988, objelivando verificar as causas em termos de planejamento ísico, do abandono de conjuntos habitacionais no Harlem, New York City (1988). Aqui, a minorla lovantada era negra, sendo que grande parte dos chefes de famila eram mulheres.

\section{Autoconstruçōes, Ajuda-Mútua e Megaconjuntos Habitacionais: Casos Distintos de Segregação Social e Espacial ldênticas}

Através da aplicação da APO, tanto no Butantã, bem como em conjuntos habitacionais do Programa de Erradicação da Sub-Habitaçāo-Promorar, do tipo ajuda mútua, em Vila Nova Cachoeirinha (Casa Verde); Parque Adventista (região Sul, próximo a Itapecerica da Serra); Nossa Senhora da Penha (regiāo Norte), na Vila Comunitária, em São Bernardo do Campo (Azevedo, 1989); no Jardim São Luiz em Santo Amaro (Ornstein, et al., 1985), ou ainda, em megaconjuntos habitacionais convencionais do tipo Itaquera, região Leste (Loureiro et al., 1989), constata-se, em menor ou maior grau, a segregação 4 do contexto urbano destes conglomerados (ou ghettos?), na forma de bolsőes de pobreza. Em todos os casos, sejam autoconstruçōes isoladas, ajudas-mútuas ou conjuntos habitacionais, tem-se como ponto em comum a super e infra-estrutura urbanas escassas e fundamentalmente a pouca qualidade e definiçāo dos espaços públicos que 
rapidamente se transformam em palco de movimentos antissociais, por se configurarem em "terra de ninguém". Será este o caminho para o equacionamento do déficit habitacional urbano com qualidade de vida?

Salvo poucas exceções, em qualquer caso que envolve habitaçōes para populaçōes de baixa renda, é raro o controle e a apropriaçăo efetivos dos espaços públicos por parte dos moradores. As autoconstruçōes são nitidamente casos individuais em que dificilmente ocorre uma preocupação "além dos limites do lote". No caso de programas governamentais de ajuda-mútua, apesar da escala mais humana dos projetos, pouco se atua em termos de organização social da comunidade em torno dos espaços públicos. A situação se agrava mais, no caso de megaconjuntos habitacionais tais como Itaquera, Carapiculba e Cidade Tiradentes. Nestes casos, em que cada conglomerado apresenta de 90 a 100.000 moradores, evidencia-se algumas tentativas governamentais de se organizar as populaçōes em projetos comunitários. Sociólogos e assistentes sociais da COHAB-SP, procuram fomentar atividades comunitárias mas, na realidade, o que se configura são relaçōes paternalistas de dependência, cujos laços são dificilmente rompidos.

Enfim, em todos os casos, há a presença de ligaçōes extremamente tênues entre estes conglomerados, através de seus espaços públicos com a trama urbana produtora e eficiente. Estes espaços públicos muitas vezes decorrentes de projetos urbanos precários e, portanto, já apresentando problemas flsicos latentes, sendo o mais comum o da erosão, têm usos indefinidos, pouca ou nenhuma manutenção, e dificilmente se transformam em focos centrais de atividades comunitárias. No entanto, experiências ocorridas em outros palses desenvolvidos e em desenvolvimento, indicam que a transferência efetiva do gerenciamento destas áreas habitacionais para os próprios moradores, fazendo com que estes tomem suas próprias decisōes, entri muito colabora para o aumento da qualidade dos espaços públicos e privados, assim como das relaçőes sociais.

\section{Futuras Linhas de Investigação para uma Nova Visăo de Politica Habitacional Umana}

Estudos recentes em palses desenvolvidos, indicam que problemas de segregação de áreas habitacionais do contexto urbano passam, necessariamente, pela delimitação da densidade ocupacional. Na França, por exemplo, estão proßbidos conjuntos habitacionais com mais de 300 unidades. Nos EUA atualmente se procura não ultrapassar 250 unidades, sendo que alguns estudos vem apontando como o ideal 50 unidades por conjunto. Outras experiências, ainda mais radicais, apontam pela inserção plena na malha urbana, de lotes urbanos individuais para famlias de baixa renda, sem obrigatoriamente reunir em um conglomerado único populaç̋̋es de baixa renda, evitando-se assim, qualquer tipo de segregação.

Constata-se, assim, que em todos os estudos de caso, o ponto crucial não é gerenciar "pelos" moradores, mas sim, em um primeiro estágio, extremamente curto, gerenciar "com" os moradores, para, em um segundo e mais importante estágio, os gerentes externos (órgãos públicos) deixarem definitivamente o conjunto, em prol do gerenciamento deste pelos próprios moradores.

Esta nova visão pode ser alcançada não sem tensões e conflitos e passa, necessariamente, pela mudança de consciência de todos os envolvidos, sejam moradores, profissionais, os órgãos públicos e as entidades polftico-sociais.

A atuação de equipes interdisciplinares de pesquisa, visando a incorporação de análises comportamentais ao método de APO, procurando observar as atividades, as relaçőes e niveis de intensidade destas atividades, horários, periodicidade e pontos de encontro poderá colaborar na alteração deste quadro. 


\section{Referências Bibliográficas}

AGGIO, Sandra M., HERLING, Tereza B, R. Conjuntos habitacionais: apropriaçбes dos espaços públicos. São Paulo: Companhia de Desenvolvimento Habitacional - $\mathrm{CDH}, 1989$. (mimeo).

ALBUQUERQUE, Marcos Cintra Cavalcanti. Habitaçáo popular: avaliaçáo e propostas de reformulaçáo do sistema financeiro da habitação. São Paulo: Fundação Getúlio Vargas, 1985 (relatório de pesquisa).

AZEVEDO, Miriam Roux. Avaliaçăo pós-ocupação em nưcleos habitacionais resultantes de regime de ajuda mútua na Regiāo Metropolitana de São Paulo, em relação a sua adaptação ao uso. In: Seminário Avaliação Pós-Uso-APU. São Paulo, 7-9/6/1989. Anais. São Paulo: FAUUSP, 1989. p. 177-186.

BECHTEL, Robert B., MARANS, Robert W., MICHELSON, William, eds, Methods in environmental and behavioral research. New York: Van Nostrand Reinhold, 1987.

CAMPOS FILHO, Cåndido M. Cidades brasileiras: seu controle ou o caos. São Paulo: Nobel, 1989.

EHRENKRANTZ, Ezra; SHOSHKES, Ellen. Balanced housing: promise, process and product an evaIuation of the balanced housing program. New Jersey: New Jersey Institute of Technology, Department of Architecture and Building Science, 1989.

FELDMAN, Sarah. Segregaçōes espaciais urbanas - a territorialização da prostituiçáo feminina em São Paulo. São Paulo, 1989. Dissertação Mestrado - FAUUSP. Orientador, Flávio Villaça.

INSTITUTO BRASILEIRO DE GEOGRAFIA E ESTATISTICA IBGE. Pesquisa nacional por amostra de domicnios - 1981. Rio de Janeiro: IBGE, 1983 (Regióes Metropolitanas).

Pesquisa nacional por amostra de domicnios - 1987. Rio de Janeiro: IBGE, 1988 (Regiōes Metropolitanas).

LEAVITT, Jacqueline; SAEGERT, Susan. The community-household: responding to housing abandonment in New York City. New York: APA Journal, outono, 1988 (APA - American Planning Association).

LOUREIRO, Claudia, ALUCCI, Marcia P., CARDIA, Nancy. Avaliação pós-ocupação em conjuntos habitacionais: um estudo de caso - Săo Paulo. In: Seminário Avaliação Pós-Uso-APU, São Paulo, 7-9/6/1989. Anais. São Paulo: FAUUSP, 1989. p. 149-175.

ORNSTEIN, Sheila Walbe. A avaliação da habitaçăo autogerida no Terceiro Mundo. São Paulo, 1988. Tese - Doutorado - FAUUSP. Orientador, Ualfrido Del Carlo.

- et all. Um modelo de análise do processo produtivo da habitaçáo autoconstrulda: o caso do Promorar do Jardim São Luiz. São Paulo: FAUUSP, 1985. (mimeo).

MARCUS, Claire Cooper, SARKISSIAN, Wendy. Housing as if people mattered. Los Angeles: University of California Press, 1986.

PREISER, Wolfgang F. E. (ed.) Building evaluation. New York: Plenum Press, 1989.

SECRETARIA MUNICIPAL DO PLANEJAMENTO. Conheça sua região. São Paulo: Projeto Editores Associados Ltda, 1985.

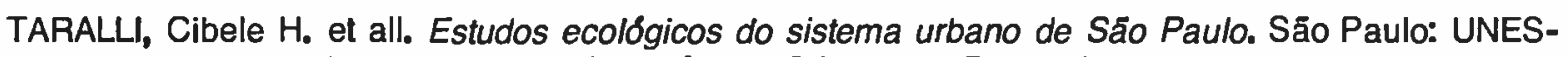
CO/MAB/FAUUSP, 1989. Mimeo (Relatório I - Sāo Miguel Paulista).

TASCHNER, Suzana P. A cidade dos "sem terra". Sinopses 9. São Paulo: FAUUSP, junho de 1986. p. 267-304.

—; MAUTNER, Yvone. Habitação da pobreza: alternativas de moradia popular em São Paulo. São Paulo: FAUUSP, 1982.

VILAÇA, Flávio. O que todo cidadāo precisa saber sobre habitação São Paulo: Global Editora, 1986. 